\title{
Morfologia e química de cinzas do vulcão Puyehue depositadas na região metropolitana de Porto Alegre em junho de 2011
}

\author{
Evandro Fernandes de Lima ${ }^{1 *}$, Carlos Augusto Sommer ${ }^{1}$, Ieda Maria Cordeiro Silva ${ }^{2}$, \\ Antenor Pacheco Netto ${ }^{2}$, Marcelo Lindenberg ${ }^{1}$, Rita de Cássia Marques Alves ${ }^{1}$
}

\begin{abstract}
Resumo Em junho de 2011, o Serviço Geológico Nacional do Chile relatou uma explosão vulcânica de ordem 5 na região de Los Ríos, no Complexo Vulcânico Puyehue - Cordón Caulle. Este abriga vulcões pleistocênicos construídos em seis grandes fases evolutivas e preserva $131 \mathrm{~km}^{3}$ de vulcanitos. O estratovulcão Puyehue (69 ka) teve seus últimos registros de explosões e efusões em 1921, 1922 e 1960. A explosão de junho de 2011 gerou uma coluna de piroclastos e gases com $10 \mathrm{~km}$ de altura e sob condições de alta temperatura. $\mathrm{O}$ ar circundante foi aquecido e incorporado, diminuindo a densidade da coluna que ascende em direção à atmosfera. $\mathrm{O}$ material piroclástico estaciona em uma zona de equilíbrio entre as densidades do meio e da cabeça da pluma, e a ação dos ventos determina a dispersão das cinzas. Em 9, 10 e 14 de junho de 2011, a Fundação Estadual de Proteção Ambiental (FEPAM-RS) coletou, em seus filtros, cinzas do Puyehue no Oitavo Distrito de Meteorologia, em Porto Alegre. As concentrações mantiveram-se abaixo dos padrões do Conselho Nacional do Meio Ambiente - CONAMA $\left(150 \mu \mathrm{g} / \mathrm{m}^{3}\right)$ e do Valor Guia $\left(\mathrm{VG}-\mathrm{OMS}=25 \mu \mathrm{g} / \mathrm{m}^{3}\right)$. A investigação, por meio do uso do microscópio eletrônico de varredura (MEV), indicou que as cinzas são finas ( 2 - 30 micra), com hábitos angulosos alongados e placoides. As terminações curvilíneas, correspondentes aos limites entre as vesículas e o magma, são vítreas (shards), ricas em $\mathrm{SiO}_{2}$ e $\mathrm{Al}_{2} \mathrm{O}_{3}$, e com conteúdos baixos de álcalis e $\mathrm{FeO}^{\mathrm{t}}$. O difratômetro obtido em tefra retrabalhada indica a presença de plagioclásio e cristobalita, sendo também observadas nos precipitados de queda estudados na Argentina.
\end{abstract}

Palavras-chave: vulcanismo; Andes; cinzas; composição; morfologia.

\begin{abstract}
Morphology and chemistry of the Puyehue volcano ashes deposited at Porto Alegre metropolitan region on June, 2011. The National Geological Survey of Chile reported a volcanic explosion of order 5 in the Los Ríos area (Volcanic Complex in Puyehue - Cordon Caulle) on June, 2011. This complex comprises Pleistocene volcanoes built in six large evolutionary phases and preserves $131 \mathrm{~km}^{3}$ of the vulcanites. The Puyehue stratovolcano (69 ky) had its last records of the explosive and effusive activity in 1921, 1922, and 1960. The explosion on June, 2011 generated a tephra and gas column of $10 \mathrm{~km}$ high under high-temperature conditions. The surrounding air was heated and incorporated reducing the density of the the column, which rises into the atmosphere. The pyroclastic material stops in a balance zone between the densities of the medium and head of the plume, and the wind action determines the dispersion of the ashes. On June 9, 10 and 14, 2011, the Fundação Estadual de Proteção Ambiental (FEPAM-RS) collected Puyehue ashes in its filters at the eighth District of the Meteorology (Porto Alegre). The concentrations remained below the Conselho Nacional do Meio Ambiente - CONAMA standards $\left(150 \mathrm{mg} / \mathrm{m}^{3}\right)$ and Guide Value (WHO-VG $\left.=25 \mathrm{mg} / \mathrm{m}^{3}\right)$. The research by using scanning electron microscope (SEM) indicated that the ashes are thin $(2-30$ microns), with elongated angular and placoid habits. The curved ends, corresponding to the boundaries between vesicles and melt, are vitreous (shards), rich in $\mathrm{SiO}_{2}$ and $\mathrm{Al}_{2} \mathrm{O}_{3}$, and show low alkali and $\mathrm{FeO}^{\mathrm{t}}$ contents. The diffractometer obtained in reworked tephra indicates plagioclase and cristobalite presence, and these minerals were also observed in the fall deposits studied in Argentina.
\end{abstract}

Keywords: volcanism; Andes; ashes; composition; morphology.

INTRODUÇÃO Fragmentos piroclásticos são produzidos por explosões ou ejeções a partir de um evento vulcânico (Wentworth \& Williams 1932), que são classificados de acordo com suas dimensões e grau de vesiculação (Figs. 1 e 2; Tab. 1). De acordo com esta classificação, cinzas vulcânicas são partículas piroclásticas com menos de $2 \mathrm{~mm}$ de diâmetro, nas quais o intervalo até $1 / 16 \mathrm{~mm}$ corresponde à cinza grossa e, quando inferior a $1 / 16 \mathrm{~mm}(0,0062 \mathrm{~mm})$, é denominado de cinza fina ou pó (Fisher 1961), como pode

\footnotetext{
${ }^{1}$ Instituto de Geociências da Universidade Federal do Rio Grande do Sul - UFRGS, Porto Alegre (RS), Brasil. E-mails: evandro. lima@ufrgs.br; casommer@sinos.net; txelo.geo@gmail.com; rita.cma@terra.com.br ${ }^{2}$ Fundação Estadual de Proteção Ambiental Henrique Luis Roessler - FEPAM, Departamento de Laboratórios/Serviço de Amostragem - SAMOST, Porto Alegre (RS), Brasil. E-mails: iedamcos@hotmail.com; pachecosemapi@yahoo.com *Autor correspondente
} 
ser visto na Fig. 1. A expressão tefra refere-se à acumulação de material piroclástico não consolidado, independente das dimensões e do modo de colocação (Tab. 1). Os mecanismos de transporte do material piroclástico são os mesmos que atuam no ambiente sedimentar: fluxo de massa, tração e suspensão. Estes são responsáveis pela geração de depósitos de fluxos piroclásticos, surges e quedas.

As partículas transportadas por um regime de suspensão e que geram os depósitos de queda podem alcançar centenas a milhares de quilômetros de distância da fonte. Esta característica explica a importância de camadas de cinzas vulcânicas como marcadores estratigráficos recentes (Freire et al. 2010, Aoki 2008, Furuta et al. 1986) ou antigos (Albarnaz et al. 2009, Guerra-Sommer et al. 2008a,b,c, Formoso et al. 1999; Calarge et al. 2006). As cinzas mais grossas são, em geral, constituídas por vidro $($ shards $=$ paredes de bolhas nos condutos dos vulcões ou gotículas de magma resfriadas imediatamente durante a explosão), eventualmente vidro mais cristais e por pequenos fragmentos do próprio edifício vulcânico (Tab. 1; Fig. 2). As cinzas muito finas ou o pó em geral correspondem a shards e produtos de cristalização da fase vapor.

A rotina e a atividade vulcânica A recente explosão do vulcão islandês Eyjafjallajokull (abril de 2010 e maio de 2011) permitiu avaliar as dificuldades impostas ao uso do espaço aéreo, quando na presença de um imenso volume de cinzas vulcânicas e gases.
Fenômenos desse tipo alteram a rotina das regiões vizinhas aos vulcões ativos, como a Argentina, que recebe materiais piroclásticos das manifestações vulcânicas geradas especialmente no sul do Chile. As frações piroclásticas finas, dependendo das direções dos ventos, podem atingir locais ainda mais distantes. Em 1987, Porto Alegre e Santa Cruz do Sul registraram a precipitação de cinzas vulcânicas e, em 1993, este fenômeno foi percebido em grande parte do estado do Rio Grande do Sul.

Em 4 de junho de 2011, o Serviço Nacional de Geologia e Mineração (SERNAGEOMIN), Observatório do Vulcão dos Andes do Sul (OVDAS), no Chile, alertou para os sinais sísmicos que precederam uma explosão na região de Los Ríos no Complexo Vulcânico Puyehue - Cordón Caulle. Segundo Singer et al. (2008), este complexo abriga um conjunto de vulcões pleistocêni$\cos$ (Fig. 3), localizados entre $40,5^{\circ} \mathrm{S}-72,2^{\circ} \mathrm{O}$, alinhados na direção Noroeste-Sudeste e oblíquos à principal frente que se posiciona sobre a falha Liquiñe-Ofqui. Esta é uma estrutura intra-arco com cerca de $1.000 \mathrm{~km}$ de comprimento, relacionada a um regime transpressivo dextral atuante no Quaternário (Lavenu \& Cembrano 1999). O complexo preserva aproximadamente $131 \mathrm{~km}^{3}$ de material vulcânico, que foi gerado a partir de numerosos condutos. Aproximadamente $80 \%$ do volume total é composto por basaltos e andesitos que formaram dois vulcões em escudo entre 314 e $70 \mathrm{ka}$. $\mathrm{O}$ estratovulcão Puyehue foi construído sobre o

Tabela 1 - Terminologia aplicada para a descrição de produtos vulcânicos

\begin{tabular}{ll}
\hline Termo & Constituinte gerado por fragmentação como resultado direto de ação vulcânica explosiva. \\
\hline Piroclasto & Fragmento oriundo diretamente do magma (essenciais): cristais, vidros e líticos. \\
\hline Piroclasto juvenil: & Vidro vulcânico altamente vesiculado (> 50\% de vesículas) (Fig. 2). \\
\hline Púmice & Vidro vulcânico altamente vesiculado de composição básica ou intermediária (Fig. 2). \\
\hline Escória & Fragmento originado da fragmentação de rochas vulcânicas comagmáticas anteriormente formadas. \\
\hline Piroclasto acessório & Fragmento oriundo de rochas encaixantes ejetadas explosivamente durante a erupção. \\
\hline Piroclasto acidental & Clasto englobado aleatoriamente durante o transporte. \\
\hline Vitroclasto (shard $)$ & $\begin{array}{l}\text { Piroclasto oriundo da fragmentação de vidro vulcânico, principalmente púmices. A morfologia deste } \\
\text { fragmento é bastante variável: meia-lua, espículas, cúspides ou filamentos (Fig. 2). }\end{array}$ \\
\hline Cristaloclasto & $\begin{array}{l}\text { Fragmento de cristais, que podem ser originados a partir do próprio magma e são capturados no ato da } \\
\text { cristalização. Como produto final tem-se cristais envolvidos nas bordas por material vítreo; podem ser } \\
\text { originados, também, a partir das rochas encaixantes. }\end{array}$ \\
\hline Litoclasto & $\begin{array}{l}\text { Fragmento de rochas; o tipo de composição mais comum é similar ao do magma que sofreu a explosão; } \\
\text { podem ser originados a partir do conduto vulcânico ou relacionados a outros tipos de rochas. }\end{array}$ \\
\hline Tefra & \begin{tabular}{l} 
Termo coletivo para depósitos piroclásticos inconsolidados. \\
\hline
\end{tabular}
\end{tabular}



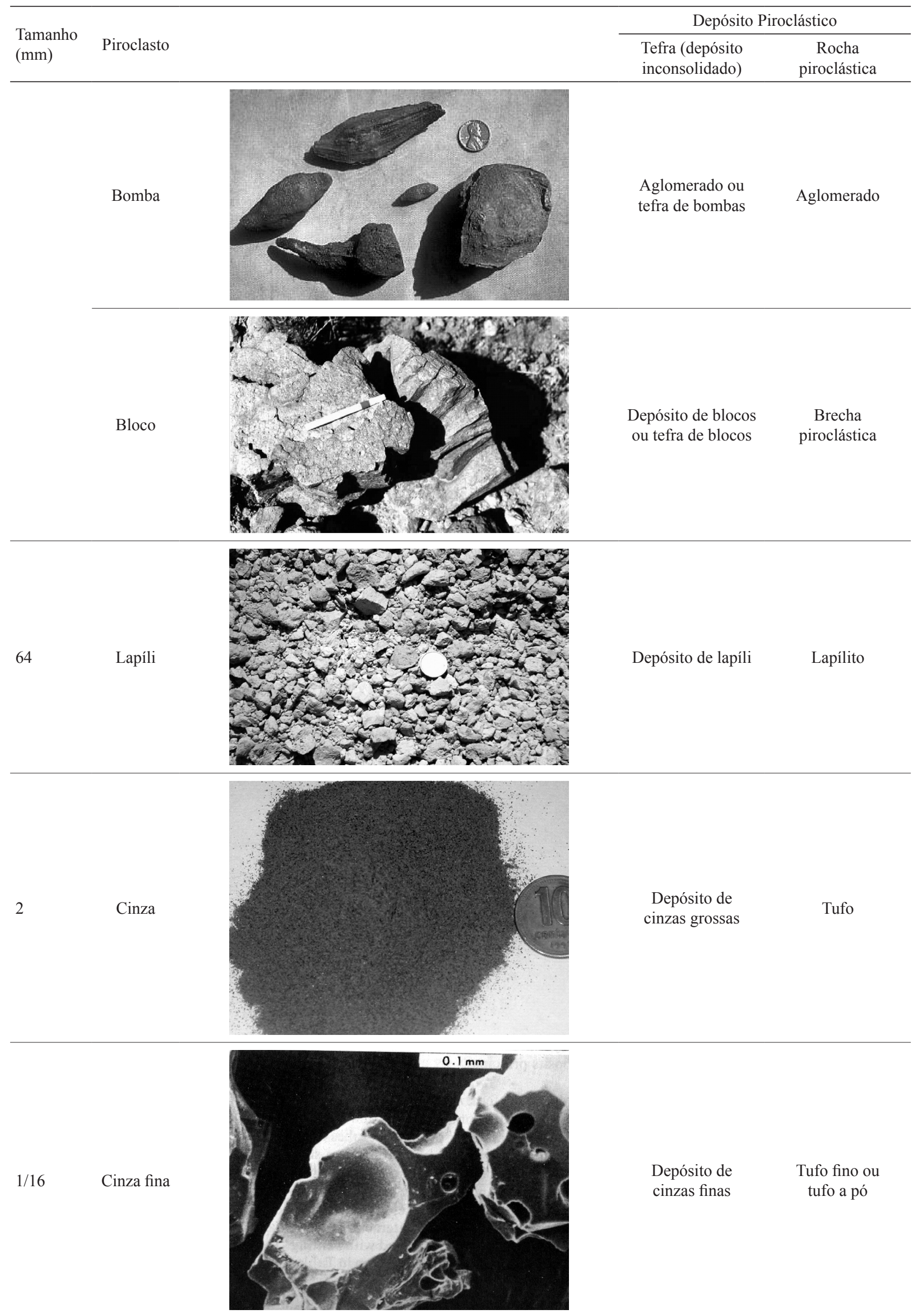

Figura 1 - Classificação e nomenclatura de depósitos piroclásticos. Modificado de Fisher (1961) e Le Maitre (2002). 

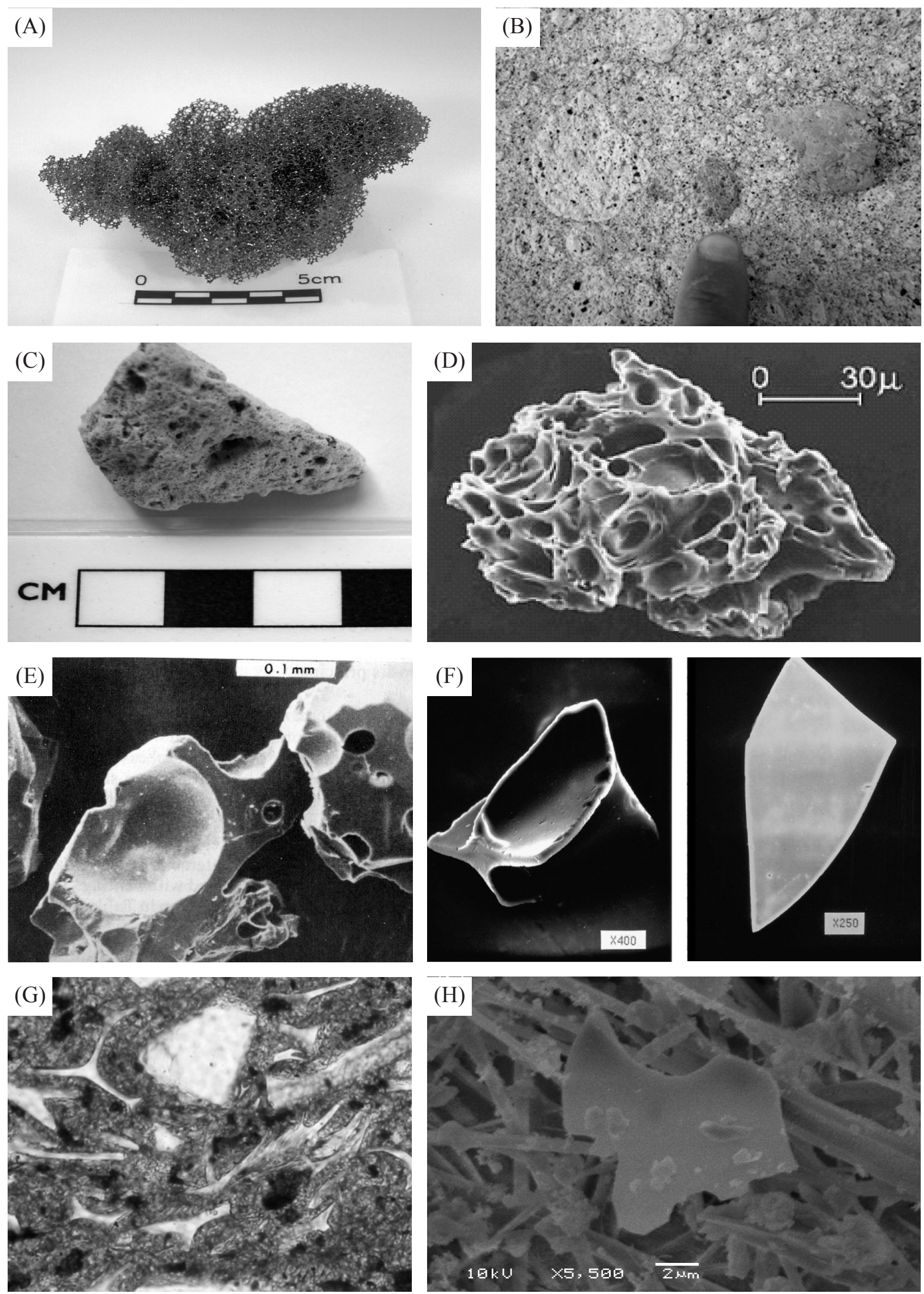

Figura 2 -Exemplos de fragmentos vitreos altamente vesiculados e vitroclastos (shards): (A) escória; (B) fragmentos de púmices em rocha piroclástica; (C) amostra de púmice; (D) fotomicrografia de púmice; (E, F) fragmentos de púmices; G) shards em lâmina delgada e (H) shards em MEV. 


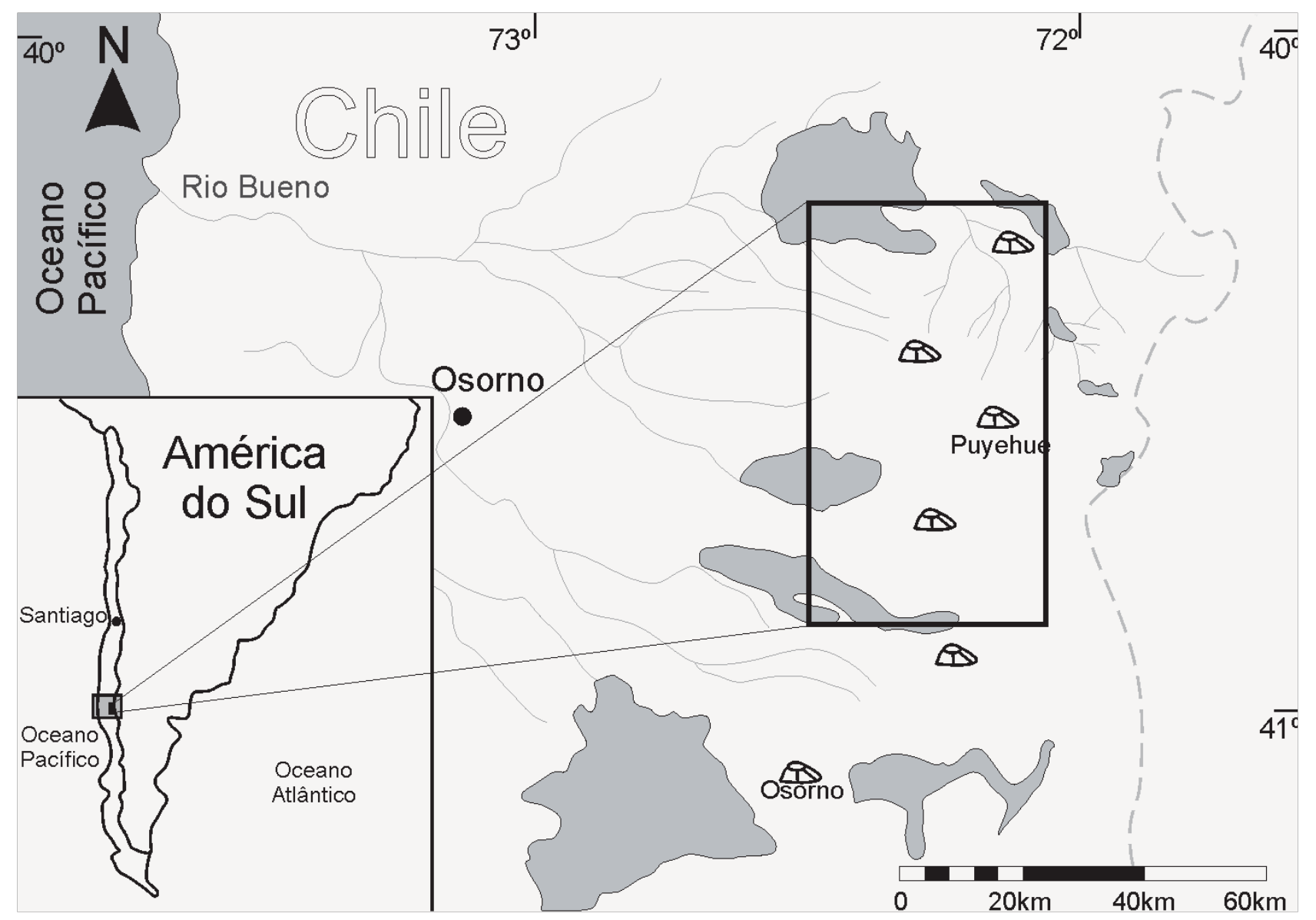

Figura 3 - Mapa de localização do Complexo Vulcânico Puyehue-Cordón Caulle. Modificado de Dorsch (2003).

escudo Sul durante os últimos 69 ka após um hiato de $25 \mathrm{ka}$. As primeiras manifestações do Puyehue foram de natureza básica, seguidas por um magmatismo riolítico. Singer et al. (2008) descreveram seis fases evolutivas do Puyehue, incluindo: magmatismo basáltico-andesítico para lavas dacíticas entre 69 e $32 \mathrm{ka}$; mudança composicional para riodacito misturado com inclusões basálticasandesíticas com alto $\mathrm{MgO}$ com $34 \mathrm{ka}$; manifestações dacíticas com riolitos em domos em $19-12$ $\mathrm{ka}$; basaltos e andesitos entre 15 e $12 \mathrm{ka}$; crescimento de domos riolíticos subsequentes em vários estágios efusivos e explosivos entre 7 e $5 \mathrm{ka}$, seguido por uma série de erupções hidromagmáticas e subplinianas em 1,1 ka, as quais obliteraram os domos riolíticos anteriores e formaram o diâmetro atual de $2,5 \mathrm{~km}$ e a profundidade de $280 \mathrm{~m}$ na cratera do Puyehue. Ao longo da zona de fissura Caulle Cordón, foram gerados cerca de $5 \mathrm{~km}^{3}$ de lavas e domos riolíticos e riodacíticos durante os últimos 16,5 ky, incluindo erupções explosivas e efusivas em 1921, 1922 e 1960.

A explosão do Puyehue em junho de 2011 gerou uma coluna de piroclastos e gases com $10 \mathrm{~km}$ de altura e com largura de $5 \mathrm{~km}$ (Fig. 4), a qual atingiu rapidamente uma extensão aproximada de $3.300 \mathrm{~km}$ e cinco episódios de fluxos piroclásticos foram desencadeados durante o colapso parcial da coluna de erupção. A elevada acumulação de material piroclástico nas cabeceiras das nascentes dos rios no Vulcão Puyehue aumentou a ocorrência de lahars secundários (fluxos de massa). A região vizinha ao vulcão recebeu um grande acúmulo de tefras e, em 20 de junho de 2011, foi registrada a primeira manifestação de lavas ácidas $\left(\mathrm{SiO}_{2}=72 \%\right)$.

Bermudez \& Delpini (2011) investigaram, nos primeiros 23 dias da erupção do Puyehue, a dispersão, a espessura e a granulometria dos depósitos de queda. Os piroclastos alcançaram as províncias de Rio Negro, Neuquén e Sul de Buenos Aires (Fig. 

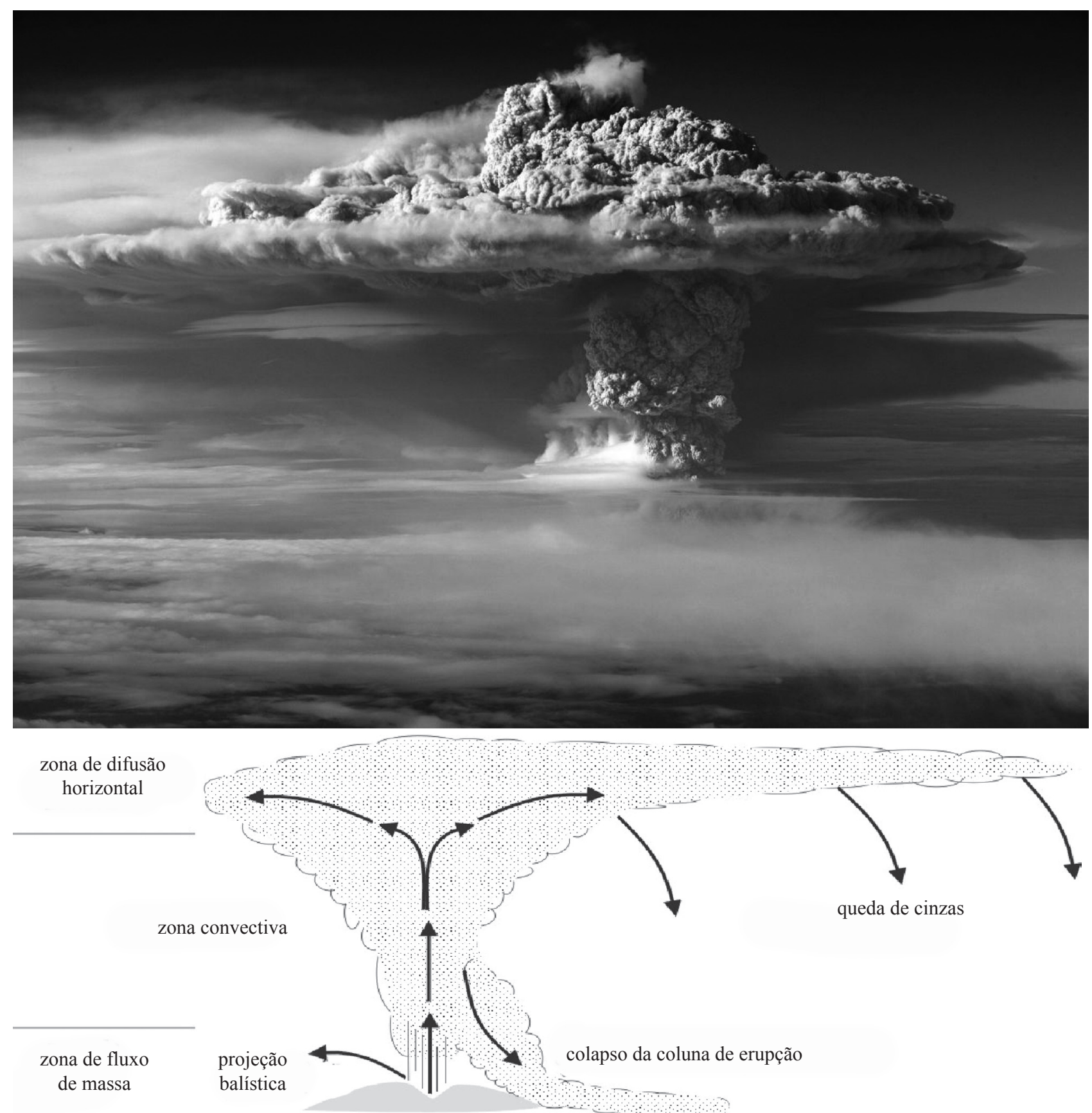

Figura 4 - Foto panorâmica da erupção de junho de 2011 do Vulcão Puyehue, situado no sul do Chile, a $920 \mathrm{~km}$ da capital (a partir de Ivan Alvarado/Reuters) e figura esquemática apresentando os principais processos em um evento vulcânico explosivo.

5). Em Villa La Angostura, Bariloche, San Martin de los Andes e Villa Traful concentraram-se bombas e blocos vulcânicos (> $32 \mathrm{~mm})$, lapíli $(32-2$ $\mathrm{mm})$, cinzas grossas $(2-0,062 \mathrm{~mm})$ e finas $(<0,062$ $\mathrm{mm})$, como observado na Fig. 6. Nos locais mais distantes, em direção a SE, como Ing. Jacobacci, Comallo (Província de Rio Negro) e Gan Gan e Gastre (Província de Chubut), as tefras acumularam espessuras entre 5 e $10 \mathrm{~cm}$. Neste setor, concentraram-se principalmente cinzas grossas e finas. Uma terceira área envolvendo um amplo setor periférico das províncias de Neuquén, Chubut e Rio Negro dominaram cinzas finas e acumulações entre 1 e 5 $\mathrm{cm}$. Finalmente, nas áreas ainda mais distantes dominam frações do tamanho pó, nos quais as espessuras decresceram para $1 \mathrm{~cm} \mathrm{e} 0,2 \mathrm{~mm}$ (Fig. 6). 


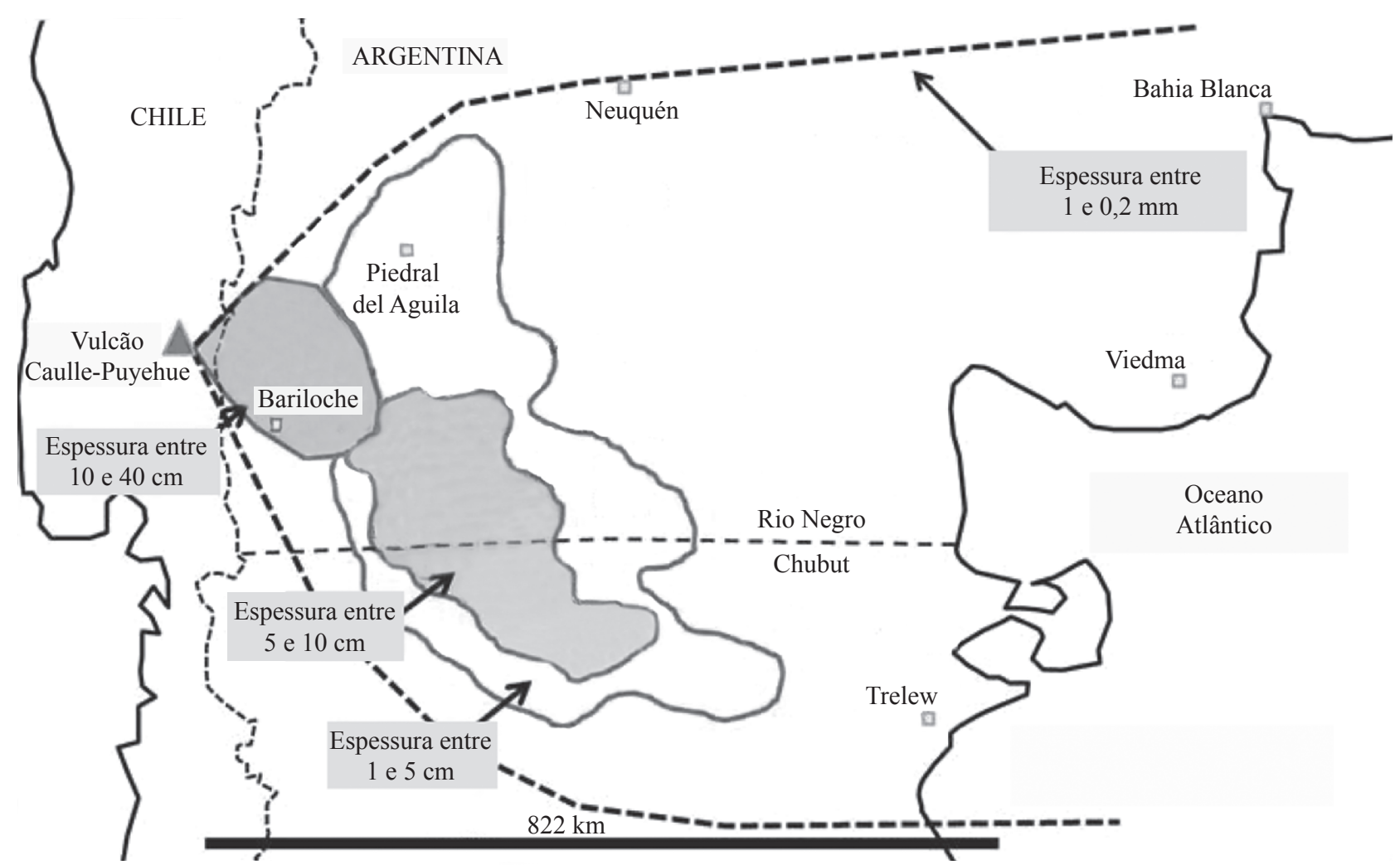

Figura 5 - Mapa esquemático mostrando a dispersão das cinzas e a espessura dos depósitos em território argentino. Modificado a partir de Bermudez \& Delpini (2011).

Em 10 de junho de 2011, uma nuvem de cinzas finas atingiu Porto Alegre, Florianópolis e Curitiba, quando o Centro de Gerenciamento da Navegação Aérea (CGNA) cancelou diversos voos no Sul do Brasil. A nuvem ficou concentrada entre 6.000 e $7.600 \mathrm{~m}$ de altitude e tal 'fenômeno' chamou a atenção da mídia e da população (Figs. 6 e 7).

As cinzas que atingiram Porto Alegre foram coletadas por técnicos da Fundação Estadual de Proteção Ambiental do Estado do Rio Grande do Sul (FEPAM-RS), em 9, 10 e 14 de junho, em filtros acoplados a estações semiautomáticas de monitoramento da qualidade do ar. Estas estações, situadas na Região Metropolitana de Porto Alegre, são utilizadas para a determinação das concentrações de partículas e dióxido de enxofre no ambiente. A colaboração entre técnicos da FEPAM e membros do Grupo de Pesquisa do Conselho Nacional de Desenvolvimento Científico e Tecnológico (CNPq) da Universidade Federal do Rio Grande do Sul (UFRGS), de Petrologia e Estratigrafia de Sequências Vulcânicas permitiu a caracterização morfológica, a composição química e a mineralogia das cinzas vulcânicas.

\section{MATERIAIS E MÉTODOS}

Coletas de amostras Em 9, 10 e 13 de junho de 2011, a FEPAM-RS, órgão responsável pela operação regular das estações semiautomáticas de monitoramento da qualidade da Região Metropolitana de Porto Alegre, coletou, em seus filtros, cinzas do vulcão Puyehue. Essas e outras partículas atmosféricas foram coletadas em filtros MP10 e/ou $\mathrm{MP}_{2,5}(<10 \mathrm{e}$ 2,5 micra). O Serviço de Amostragem (SAMOST) da FEPAM efetuou duas coletas extraordinárias de $\mathrm{MP}_{10}$ e $\mathrm{MP}_{2,5}$ nos amostradores instalados no Oitavo Distrito de Meteorologia em Porto Alegre.

$\mathrm{Na}$ determinação das frações $\mathrm{MP}_{10}$ e $\mathrm{MP}_{2,5}$, empregou-se o método do amostrador de grande volume (AGV), com um separador inercial de partículas acoplado ao mesmo. $\mathrm{O} \mathrm{AGV} \mathrm{MP}_{10}$ difere do $\mathrm{MP}_{2,5}$ pelo ponto de corte da cabeça de separação. O AGV aspira uma certa quantidade de ar ambiente, que passa através de um filtro dentro de uma casinhola de 

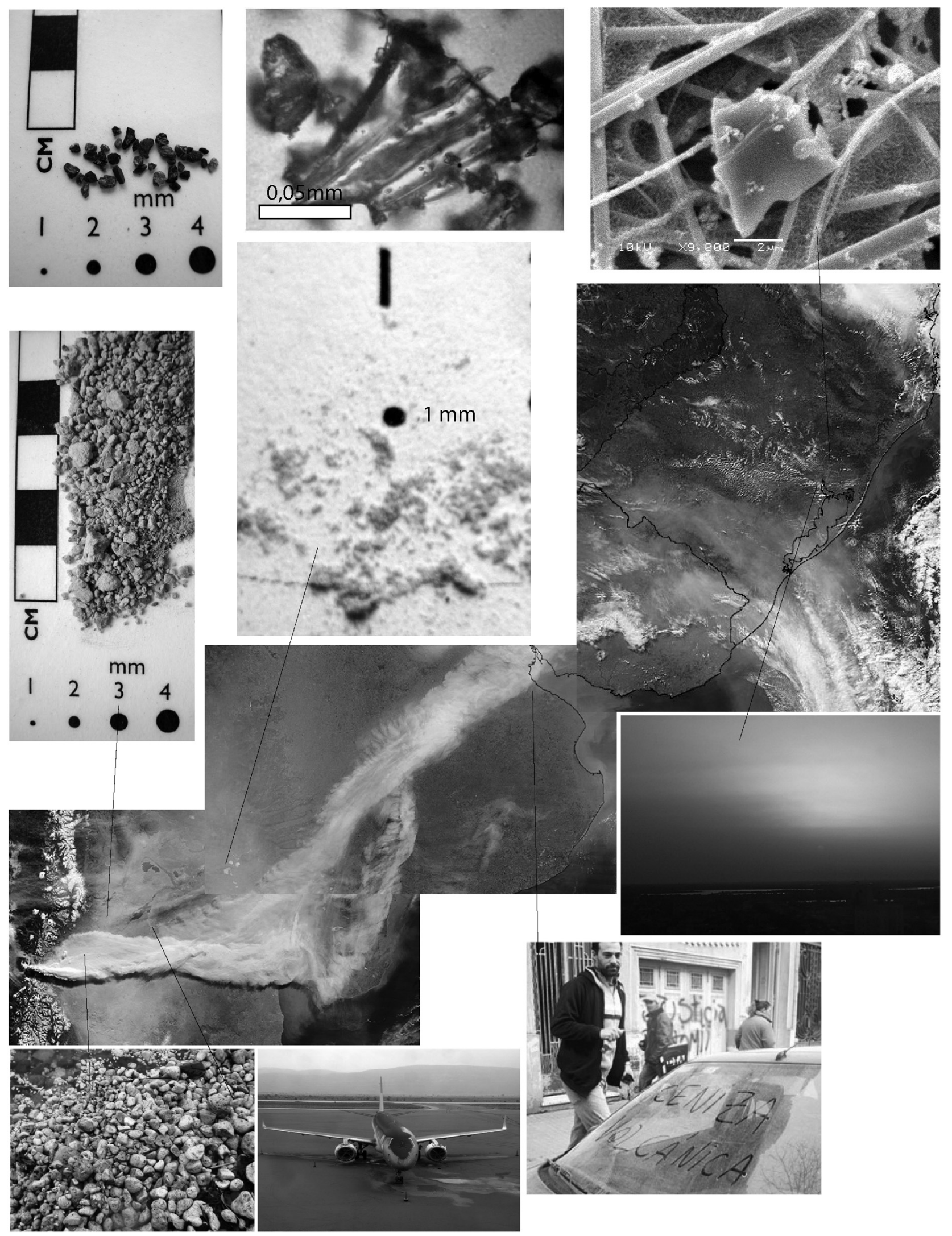

Figura 6-Figura esquemática mostrando a dispersão do material particulado emitido pelo Vulcão Puyehue, durante a erupção de junho de 2011, e a relação da distância com o volume e as dimensões das cinzas depositadas. Modificado a partir de METSUL (2011) e Bermudez \& Delpini (2011). 


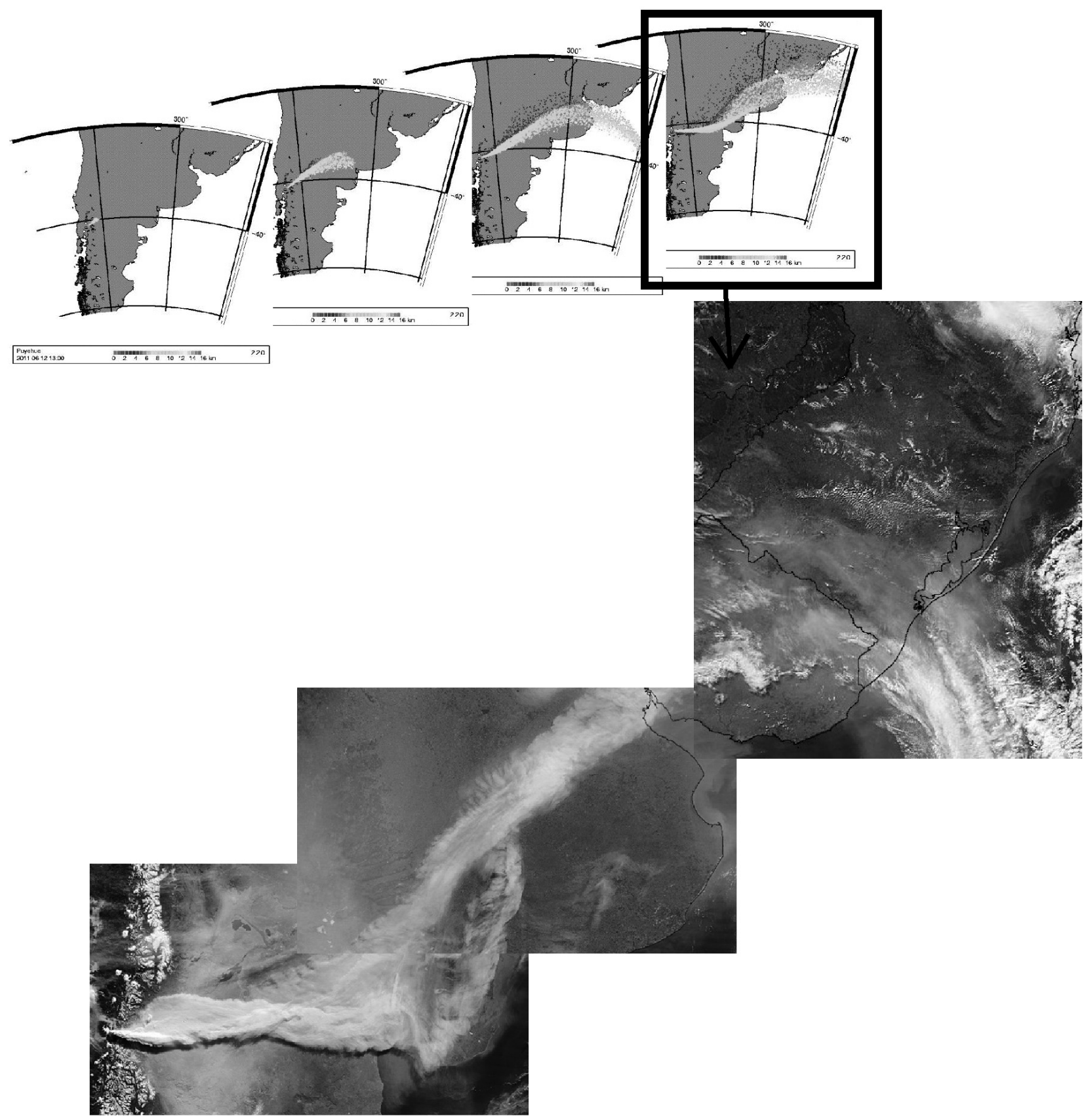

Figura 7 - Imagem de satélite de alta resolução e modelos de dispersão das cinzas vulcânicas, decorrentes da erupção do Vulcão Puyehue em junho de 2011 (extraído de www.metsul.com).

Tabela 2 - Resultados obtidos a partir da análise do material particulado coletado nos filtros

\begin{tabular}{|c|c|c|c|c|c|}
\hline Data & Número do filtro & Poluente & Massa (g) & Volume* (m3) & Concentração* $\left(\mu \mathrm{g} / \mathrm{m}^{3}\right)$ \\
\hline \multirow[t]{2}{*}{$09 / 06 / 11$} & $098 / 11$ & $\mathrm{MP}_{10}$ & 0,0531 & 1636,77 & 32,44 \\
\hline & $019 / 11$ & $\mathrm{MP}_{2,5}$ & 0,0208 & 1610,24 & 12,92 \\
\hline \multirow[t]{2}{*}{$14 / 06 / 11$} & $111 / 11$ & $\mathrm{MP}_{10}$ & 0,1157 & 1629,08 & 71,02 \\
\hline & $022 / 11$ & $\mathrm{MP}_{2,5}$ & 0,0300 & 1659,54 & 18,08 \\
\hline
\end{tabular}

\footnotetext{
*nas condições padrão de $25^{\circ} \mathrm{C}$ e $760 \mathrm{mmHg}$.
} 

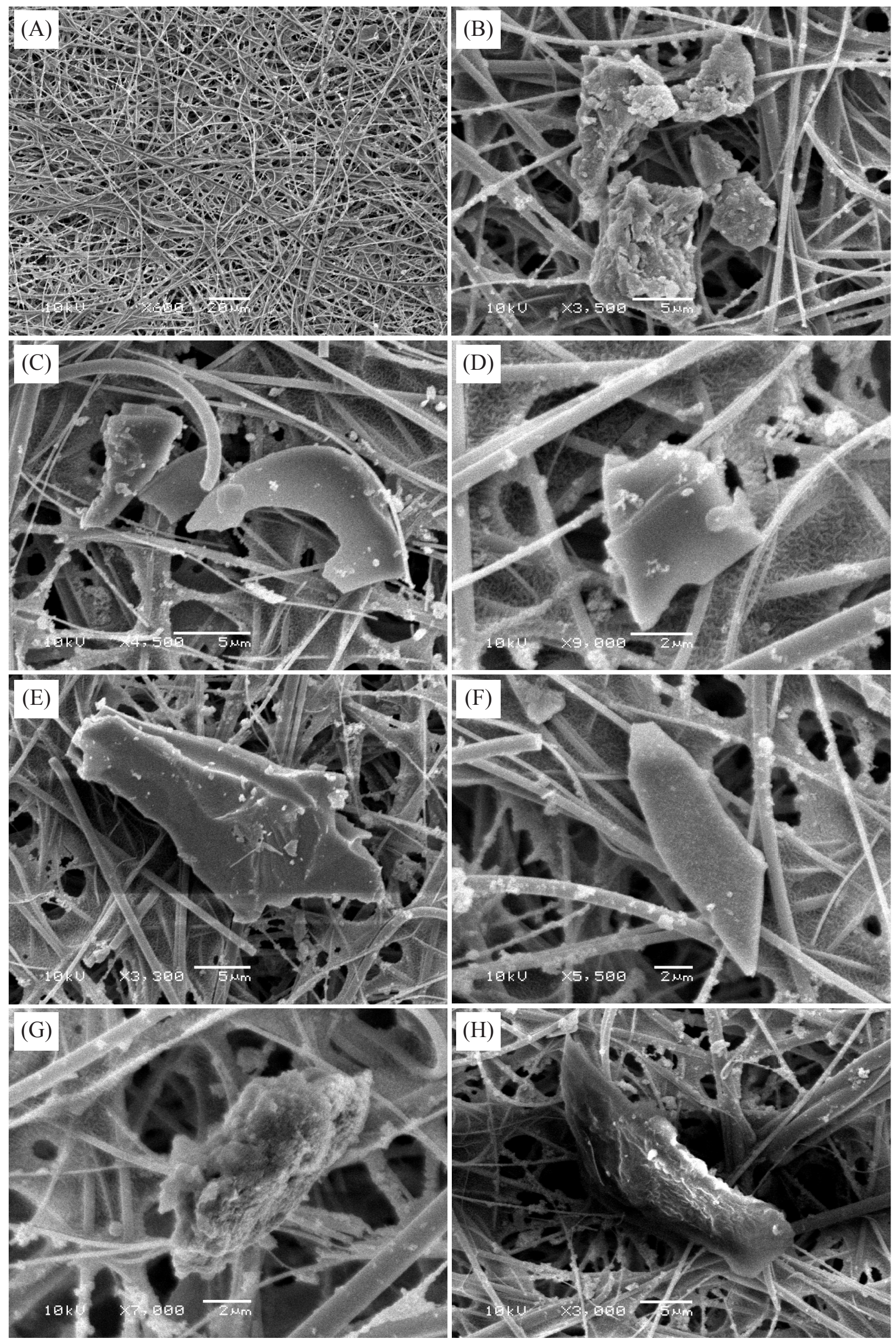

Figura 8 - Fotomicrografias mostrando o aspecto geral do filtro membrana utilizado para a coleta de cinzas (A) e as diferentes morfologias observadas nas cinzas coletadas em Porto Alegre, em 9 de junho de 2011 (B-H). 
abrigo, durante um período de amostragem de 24 horas. A duração da amostragem é controlada por um programador de tempo (timer) e medida com um horâmetro. A vazão imprimida pelo aparelho, em torno de $1,13 \mathrm{~m}^{3} / \mathrm{min}$, e a geometria da entrada da cabeça de separação favorecem a coleta das partículas com o diâmetro aerodinâmico especificado.
Para a coleta de $\mathrm{MP}_{10} \mathrm{e} \mathrm{MP}_{2.5}$, foram empregados filtros de quartzo EQTZ08x10IN e de membrana, EMFAB TX40HI20-WW, respectivamente. Cada filtro foi pesado seguindo procedimentos especificados pela NBR 9547, antes e após a coleta, para determinação do seu ganho líquido em massa. O volume de ar amostrado, corrigido para condições padrão
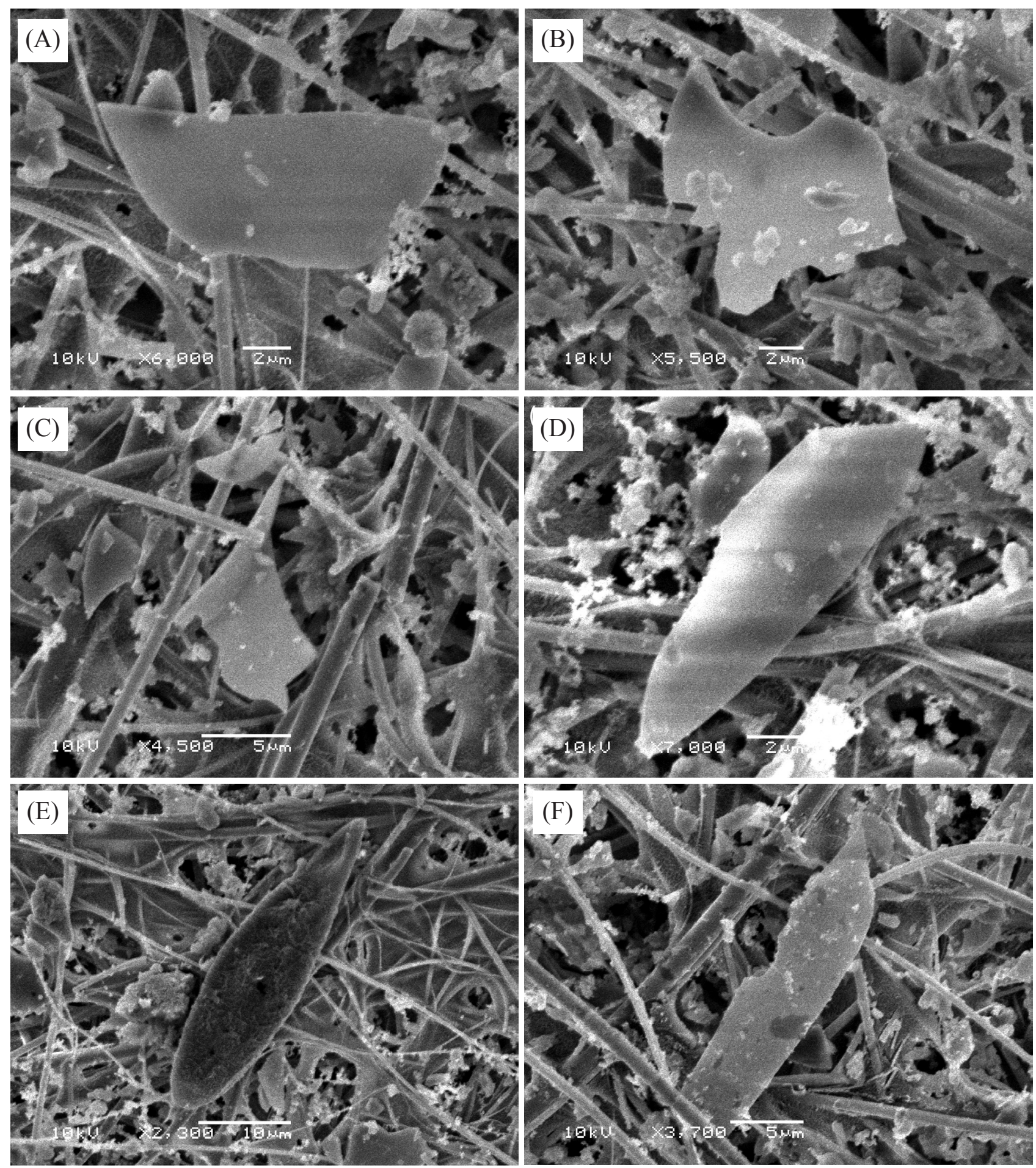

Figura 9 - Fotomicrografias com as diferentes morfologias observadas nas cinzas coletadas em Porto Alegre, em 14 de junho de 2011. 

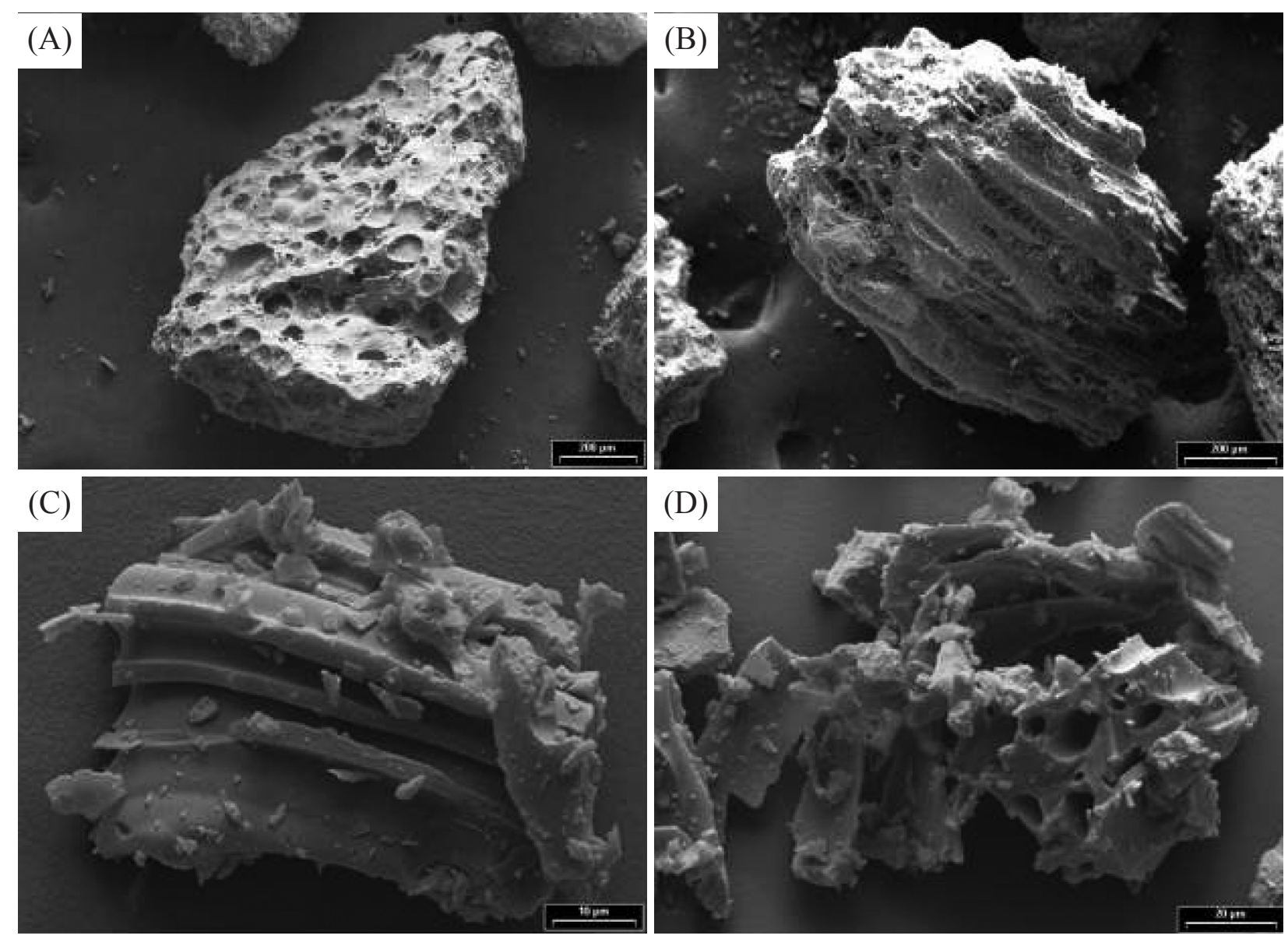

Figura 10 - Fotomicrografias de cinzas coletadas na região de Bariloche $(A, B)$ e Confluencia (C, D) Argentina: (A) textura vesicular em fragmentos de púmices; $(B, C, D)$ textura fluidal em fragmentos de púmices. Modificado a partir de Caneiro et al. (2011).

$\left(25{ }^{\circ} \mathrm{C}, 760 \mathrm{mmHg}\right)$, foi determinado a partir da vazão medida e do tempo de amostragem. A concentração de partículas no ar ambiente é calculada dividindo-se a massa de partículas coletada pelo volume de ar amostrado e é expressa em microgramas por metro cúbico $\left(\mu \mathrm{g} / \mathrm{m}^{3}\right)$.

O método do AGV MP10 encontra-se descrito na NBR 13412 da Associação Brasileira de Normas Técnicas (ABNT). Os métodos para determinação do AGV PTS e MP10 são baseados no método da United States Environmental Protection Agency (US EPA), Reference Method for the Determination of Suspended Particulates in the Atmosphere (High-Volume Method), contido no Federal Register 40 CFR 50, Appendix B, USA, versões de 1972 e 1988. Quanto ao AGV $\mathrm{MP}_{2,5}$, este não é considerado método de referência pela USEPA e não há normas nacionais especificadas (ENERGÉTICA).
Microscopia eletrônica de varredura e difratometria de raios $\mathbf{X}$ Foram realizadas três sessões para estudos relacionados à morfologia e à composição química das cinzas no Centro de Microscopia Eletrônica da UFRGS. Utilizou-se o microscópio eletrônico de varredura JEOL JSM 5800 e um energy dispersive $X$-ray detector (EDS) acoplado para obtenção dos dados químicos. Na obtenção das fotomicrografias, utilizou-se o microscópio eletrônico de varredura JEOL JSM 6060. A metalização foi realizada com cobertura por $\mathrm{C}$ e $\mathrm{Au}$.

Dados de difratometria de raios X (SIEMENSBRUKER-AXS, modelo D50000) foram obtidos sob condições de $40 \mathrm{kV}$ e $25 \mathrm{~mA}$ para radiação $\mathrm{K} \alpha$ em tubo de cobre. A amostra para difratometria foi coletada na região do Campus do Vale da UFRGS em 18 e 19 de outubro de 2011. A fração granulométrica das cinzas analisadas corresponde ao tamanho cinza fina ou pó $(<0,062 \mathrm{~mm})$, o que dispensou o processo 
(A)

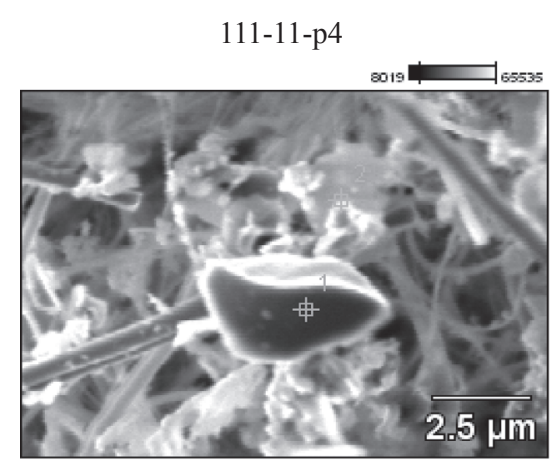

Full scale counts: 1813

111-11-p4_pt1

Cursor: $\quad 5.642 \mathrm{keV}$

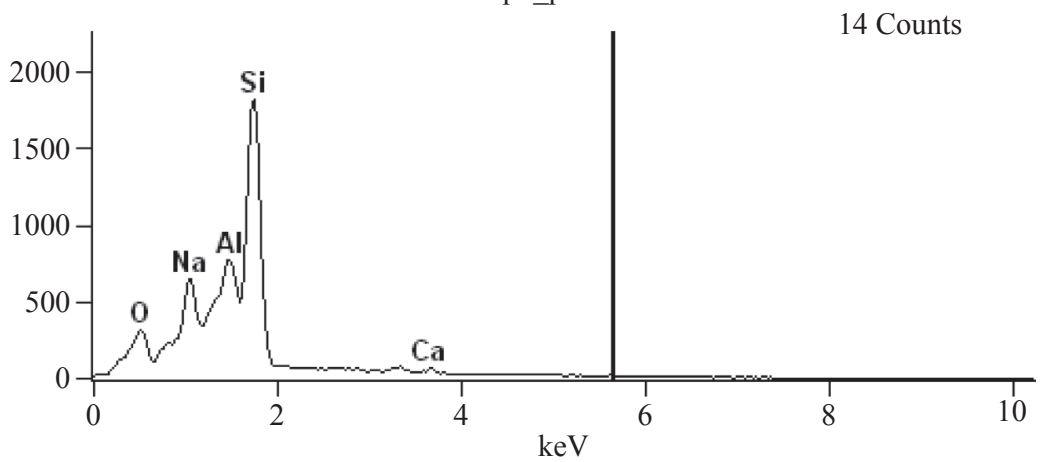

Full scale counts: 1886

111-11-p4_pt2

Cursor: $5.642 \mathrm{keV}$ 15 Counts

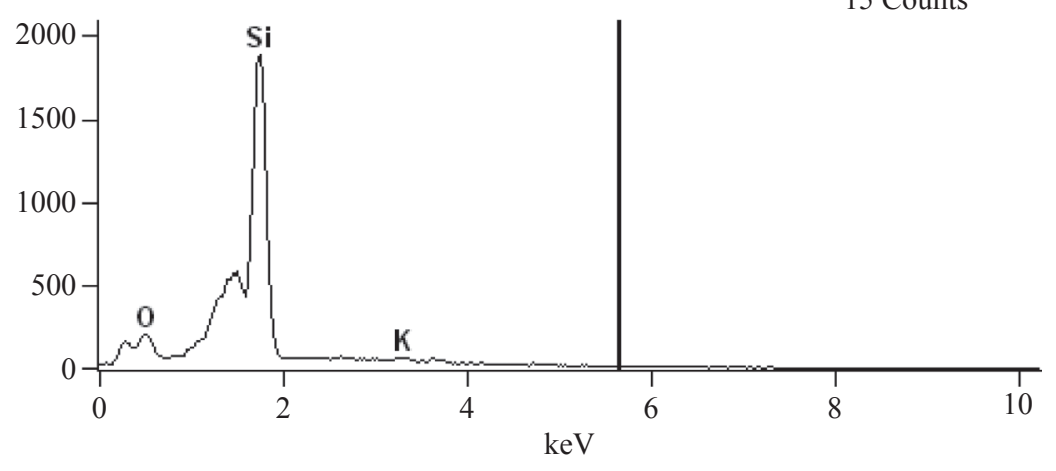

(B)

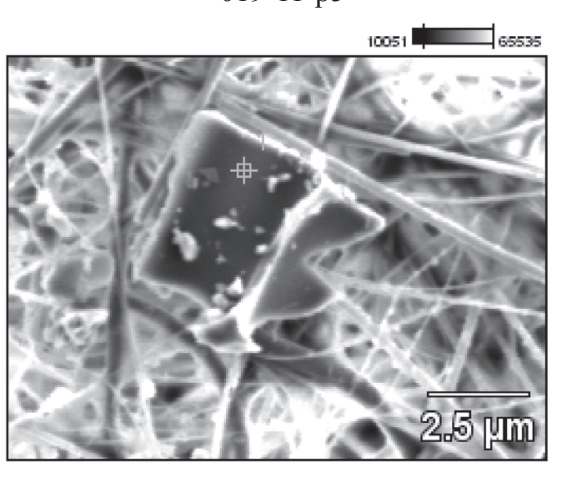

Full scale counts: 2248

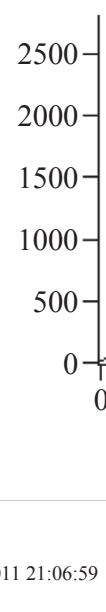

019-11-p15_pt1

Cursor: $\quad 5.642 \mathrm{keV}$
(C)

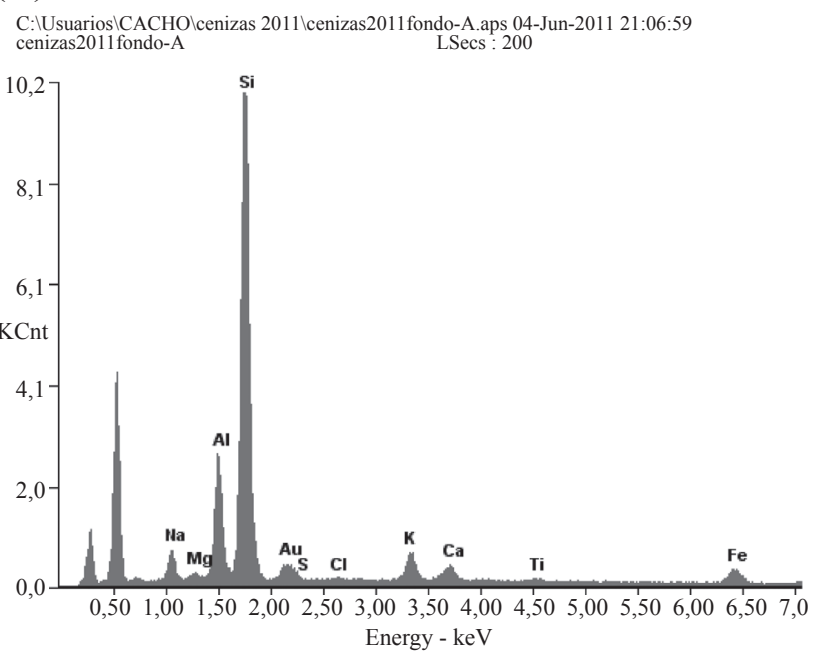

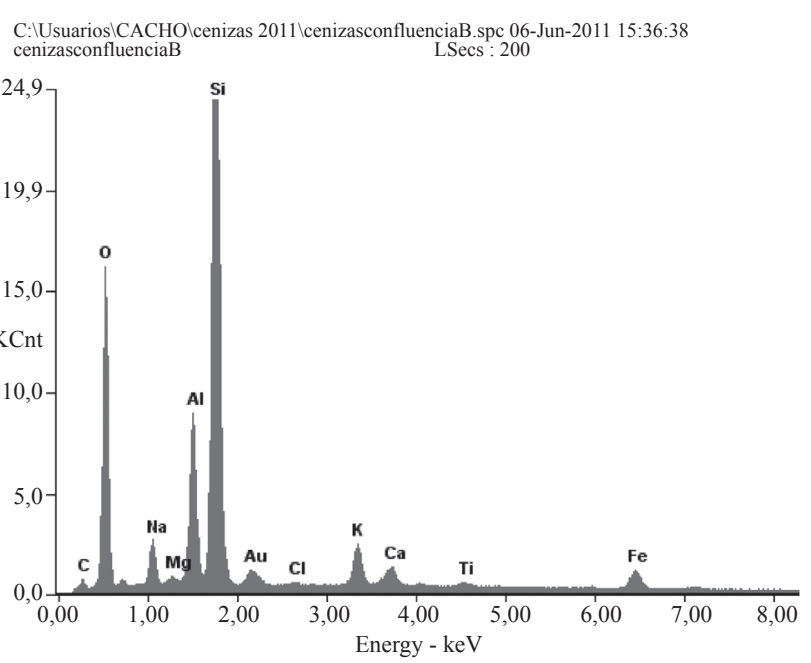

Figura 11 - Análises EDS feitas no MEV em cinzas vulcânicas originadas da erupção do vulcão Puyehue: (A, B) material coletado em Porto Alegre, respectivamente, em 14 e 9 de junho; (C) material coletado na região de Confluencia em 04 e 06 de junho (a partir de Caneiro et al. 2011). 

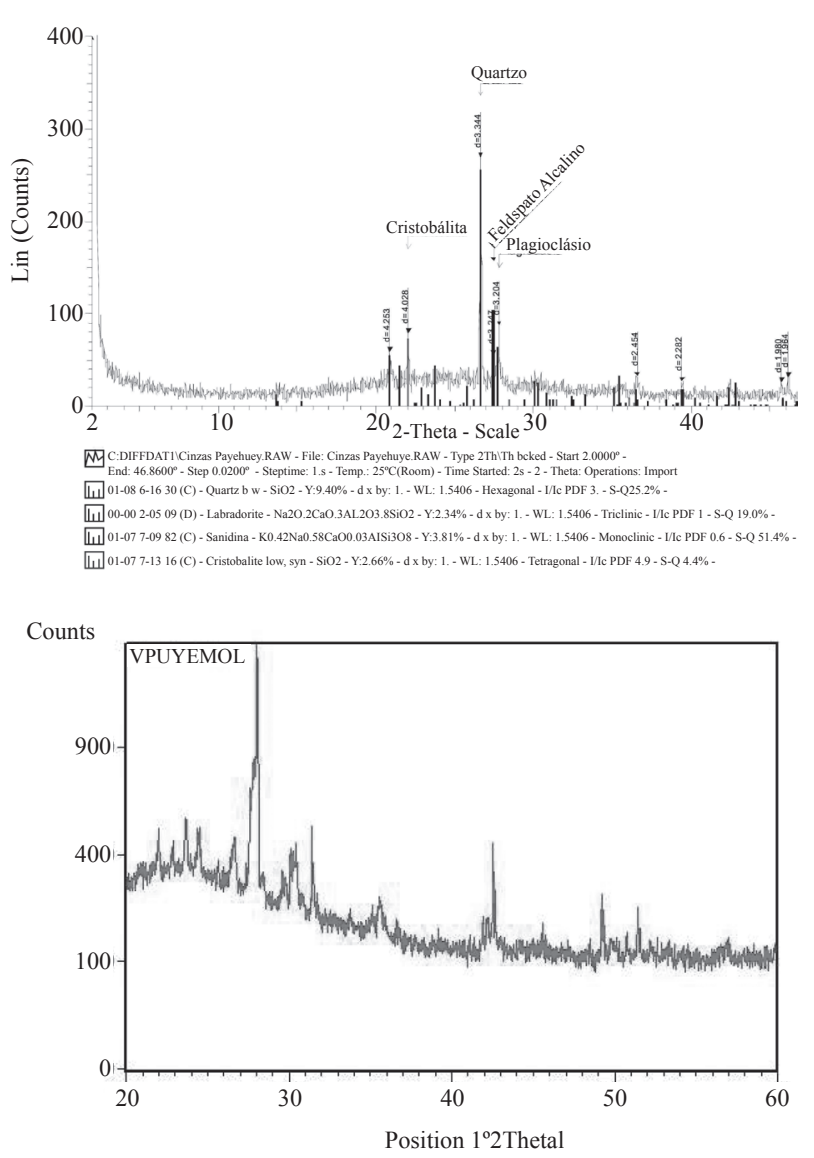

Figura 12 - Resultados da difratometria de raios $X$ realizada em cinzas coletadas em Porto Alegre (17 a 18 de outubro de 2011) e na região de Confluencia (06 de junho de 2011 - a partir de Caneiro et al. 2011).

de moagem, garantindo-se a preservação do material cristalino.

RESULTADOS E DISCUSSÃO A concentração de partículas nos filtros selecionados é apresentada na Tab. 2. As concentrações medidas mantiveramse abaixo do padrão estabelecido pela Resolução do Conselho Nacional do Meio Ambiente (CONAMA) 03/90 (padrões de qualidade do ar - $150 \mu \mathrm{g} / \mathrm{m}^{3}$ ), aplicável ao $\mathrm{MP}_{10}$ (ou PI10) e ao valor guia (VG), que é recomendado pela Organização Mundial de Saúde OMS $\left(25 \mu \mathrm{g} / \mathrm{m}^{3}\right)$ para $\mathrm{MP}_{2,5}$. Elevadas concentrações de partículas inferiores a 10 micra são consideradas nocivas aos seres humanos.

Morfologia dos fragmentos Ao microscópio eletrônico de varredura (MEV), observa-se que as partículas piroclásticas são granulometricamente muito finas (2 - 30 micra), correspondendo à fração cinza fina ou pó com hábitos angulosos alongados e placoides.
Essas morfologias são típicas de shards vulcânicos (pequenos fragmentos vítreos), que correspondem a paredes de bolhas rompidas pela explosão. Os fragmentos eram maciços, e não foram observadas microvesiculações. Os limites dos grãos são, em alguns casos, cúspides, comuns pela fragmentação de material vítreo (isotrópico), e as terminações mais curvilíneas correspondem ao limite entre a vesícula e o magma (Figs. 8 e 9).

Produtos piroclásticos do vulcão Puyehue foram também coletados por Caneiro et al. (2011) na Argentina, região de Bariloche (100 km SE do vulcão) e Confluencia (90 km a Leste do vulcão), como observado nas Figs. 5 e 6 . Nestas regiões, os depósitos de queda alcançaram espessuras da ordem 10 a 40 $\mathrm{cm}$ durante junho. Os produtos piroclásticos marcam depósitos proximais com fragmentos da ordem 1 a $5 \mathrm{~cm}$ e correspondem granulometricamente à lapíli e à cinza grossa com texturas vesiculada (púmices), fluidal (púmices de zona de conduto) e maciça, além de fragmentos conatos (Fig. 10). Os piroclastos de Confluencia são mais finos e correspondem a cinzas vítreas com morfologias cúspide, curvilínea e placas (Fig. 10).

Composição mineralógica e química Estudos sobre a química (MEV-EDS) das partículas vulcânicas depositadas na região metropolitana de Porto Alegre mostram que estes fragmentos são constituídos por óxidos de $\mathrm{SiO}_{2}$ e $\mathrm{Al}_{2} \mathrm{O}_{3}$, além de conteúdos moderados a baixos de álcalis $\left(\mathrm{Na}_{2} \mathrm{O}+\mathrm{K}_{2} \mathrm{O}\right)$ e $\mathrm{FeO}^{\mathrm{t}}$. A natureza vítrea dos fragmentos permite assumir tal composição como representativa da porção não cristalizada do magma e equivalente a magmas riolíticos (Fig. 11). Os fragmentos vítreos constituídos essencialmente por $\mathrm{SiO}_{2}$ foram interpretados como representativos da cristalização da fase vapor.

Caneiro et al. (2011), utilizando o mesmo método, analisaram partículas vulcânicas precipitadas na região de Bariloche e de Confluencia. A composição química obtida foi semelhante aos resultados obtidos no presente trabalho (Fig. 11). Estes autores realizaram também estudos de difratometria, os quais apontaram plagioclásio e quartzo como fases cristalinas e um conteúdo elevado de vidro vulcânico (Fig. 12).

Resultados semelhantes de difratometria foram obtidos nas cinzas vulcânicas coletadas em 17 e 18 de outubro de 2011, em Porto Alegre. No difratograma, caracterizou-se a presença de quartzo, plagioclásio, feldspato alcalino e cristobalita (Fig. 
12). Esta última, constituída por $\mathrm{SiO}_{2}$, é interpretada como a cristalização da fase vapor. $\mathrm{O}$ material coletado corresponde ao retrabalho das tefras pela ação dos ventos na região da Patagônia, e a presença mais abundante de quartzo pode ser atribuída à contaminação.

\section{CONCLUSÕES A elevada explosividade do} vulcão Puyehue (grau 5) explica a grande fragmentação responsável pela geração de produtos piroclásticos grossos até muito finos, fato comum em erupções hidromagmáticas. A erupção na zona do conduto ejeta de forma violenta uma grande concentração de fragmentos piroclásticos mais gases, sob condições de alta temperatura, e, gradativamente, aquece o ar circundante. Nesta etapa, a densidade da coluna eruptiva diminui, pois é influenciada pela inflação da pluma imposta pela expansão do ar aquecido. Este processo facilita a ascensão das partículas finas em direção à atmosfera. Finalmente, a pluma estaciona em uma zona onde se equilibra com a densidade do ar, sendo, a partir desta etapa, dispersa lateralmente às cinzas (efeito guarda-chuva) pela ação dos ventos (Fig. 4). Esta última fase explica a dispersão de piroclastos finos por grandes distâncias, conforme observado em 6 de junho de 2011, em Porto Alegre.
Granulometricamente, as partículas que atingiram a região metropolitana correspondem a cinzas finas e as morfologias são compatíveis com shards.

Dados da composição química destas partículas indicam uma atividade explosiva de um sistema vulcânico ácido, muito rico em $\mathrm{SiO}_{2}$. Os conteúdos elevados de óxidos "leves" $\left(\mathrm{SiO}_{2}\right.$ e $\left.\mathrm{Al}_{2} \mathrm{O}_{3}\right)$ devem ter influenciado positivamente a manutenção das cinzas em suspensão.

Dados da difratometria de raios $\mathrm{X}$ obtidos em tefras retrabalhadas indicam mineralogia semelhante à obtida nos depósitos de queda estudados na Argentina.

As concentrações de partículas medidas mantiveram-se abaixo dos padrões estabelecidos pelo CONAMA $\left(150 \mu \mathrm{g} / \mathrm{m}^{3}\right)$ e pelo $\mathrm{VG}$, recomendado pela OMS $\left(25 \mu \mathrm{g} / \mathrm{m}^{3}\right)$.

AGRADECIMENTOSAo CNPq pelas bolsas de produtividade (proc. 303038/2009-8 e 303584/2009-2). Ao professor Dr. André Sampaio Mexias e ao técnico Renato Figueira da Silva pelo auxílio na obtenção dos dados de difratometria de raios X (IG-UFRGS). Aos técnicos da FEPAM, Nádia Boeira e Ubirajara Tiarajú Santos Soares, pela colaboração científica. Aos revisores da Revista Brasileira de Geociências pelas correções e contribuições.

\section{Referências}

Albarnaz L.D.T., Dani N., Formoso M.L.L., Mexias A.S., Lisboa N.A. 2009. A jazida de Bentonita de Bañado de Medina, Melo, Uruguai. Pesquisa em Geociências, 36:263-281.

Aoki K. 2008. Revised age and distribution of ca. 87 ka Aso-4 tephra based on new evidence from the northwest Pacific Ocean. Quaternary International, 178: $100-118$.

Bermudez A. \& Delpini D. 2011. La actividad el Complejo Volcánico Puyehue - Cordón Caulle y su impacto sobre el territorio de la RepúblicaArgentina. Segundo Informe. Neuquén, 27 de Junio de 2011. 1-16p. Disponível em: http://www.conicet.gov.ar/webfiles/2011/06/. Acesso em: 10/10/2011.

Calarge L.M., Meunier A., Lanson B., Formoso M.L.L. 2006. Chemical signature of two Permian volcanic ash deposits within a bentonite bed from Melo, Uruguay. Anais da Academia Brasileira de Ciências, 78:525-541.

Caneiro A., Mogni L., Serquis A., Cotaro C., Wilberger D., Ayala C. et al. 2011. Análisis de cenizas volcánicas Cordón Caulle (Complejo Volcánico Puyehue-Cordón Caulle) Erupción 4 de Junio de 2011. Informe Cenizas Volcánicas - CNEA. p. 1-7.
Dorsch K. 2003. Hydrogeologische Untersuchungen der Geothermalfelder Puyehue und Cordón Caulle, Chile. Dissertação de Mestrado, Universidade de Munique, Munique, $179 \mathrm{p}$.

Fisher R.V. 1961. Proposed classification of volcaniclastic sediments and rocks. Geological Society of America Bulletin, 72:1409-1414.

Formoso M.L.L., Calarge L.M., Garcia A.J.V., Alves D.B., Gomes M.E.B., Mizusaki A.M.P. 1999. Permian tonsteins from the Parana Basin, Rio Grande do Sul, Brazil. In: Clay Conference Ottawa, 11, Anais, 613621.

Freire A.F.M., Sugai T., Matsumoto R. 2010. O uso de cinzas vulcânicas para correlações estratigráficas na margem leste do Mar do Japão. Boletim de Geociências da Petrobrás, 18(1):97-121

Furuta T., Fujioka K., Arai F. 1986. Widespread submarine tephras around Japan. Marine Geology, 72:125-142.

Guerra-Sommer M., Cazzulo-Klepzig M., Formoso M.L.L., Menegat R., Mendonça Filho J.G. 2008. U-Pb dating of tonstein layers from a coal succession of the southern Paraná Basin (Brazil): Anew geochronological approach. Gondwana Research, 14:474-482. 
Guerra-Sommer M., Cazzulo-Klepzig M., Menegat R., Formoso M.L.L., Basei M.A.S., Barboza E.G. et al. 2008. Geochronological Data from Faxinal Coal Succession in Southern Paraná Basin: a Preliminary Approach Combining Radiometric U-Pb Age and Palynostratigraphy. Journal of South America Earth Sciences, 25:246-256.

Guerra-Sommer M., Cazzulo-Klepzig M., Santos J.O.S., Hartmann L.A., Ketzer J.M.M., Formoso M.L.L. 2008. Radiometric age determination of tonsteins and stratigraphic constrains for the Lower Permian coal succession in Southern Paraná Basin, Brazil. International Journal of Coal Geology, 74:13-27.

Lavenu A. \& Cembrano J., 1999. Compressional and transpressional stress pattern for Pliocene and Quaternary brittle deformation in fore arc and intra-arc zones (Andes of Central and Southern Chile). Journal of Structural Geology, 21:1669-1691.
Le Maitre R.W. 2002. Igneous rocks: a classification and glossary of terms. Recommendations of the International Union of Geological Sciences Subcommission on the Systematic of Igneous Rocks, $2^{\text {nd }}$ ed., Cambridge, Cambridge University Press, 252 p.

METSUL METEOROLOGIA 2011. Cinzas vulcânicas cobrem o Cone Sul. Disponível em: http://www.metsul. com. Acesso em: 21/10/2011.

Singer B.S., Jichal B.R., Harper M.A., Naranjo J.A., Lara L.E., Moreno-Roa H. 2008. Eruptive history, geochronology, and magmatic evolution of the Puyehue-Cordón Caulle volcanic complex, Chile. Geologial Society of America Bulletin, 120(5-6):599618.

Wentworth C.K. \& Williams H. 1932. The classification and terminology of the pyroclastic rocks: Nat. Res. Council Bulletin, 89:19-53. 